\title{
Educación en línea en tiempos de COVID-19 en el área económico-administrativa en la Universidad Tecnológica de León
}

\section{Online education in times of COVID-19 in the administrative economic area of the Universidad Tecnológica de León}

\author{
QUEZADA-FLORES, Ma. de la Luz†*, MÁRQUEZ-DE ANDA, Camilo, SERRANO-TORRES, Ma. \\ Guadalupe y GONZÁLEZ-ARREDONDO, Liliana
}

Universidad Tecnológica de León, México.

ID $1^{\mathrm{er}}$ Autor: Ma. de la Luz, Quezada-Flores / ORC ID: 0000-0002-4726-2695, CVU CONACYT ID: 801109

ID $1^{\text {er }}$ Coautor: Camilo, Márquez-De Anda / ORC ID: 0000-0002-6800-0811

ID $2^{\text {do }}$ Coautor: Ma. Guadalupe, Serrano-Torres / ORC ID: 0000-0003-2229-6925, CVU CONACYT ID: 679788

ID $3{ }^{\text {er }}$ Coautor: Liliana, González-Arredondo / ORC ID: 0000-0002-1692-9602, CVU CONACYT ID: 563829

DOI: $10.35429 / J U P .2020 .12 .4 .1 .10$

Recibido 10 de Julio, 2020; Aceptado 30 de Diciembre, 2020

\begin{abstract}
Resumen
La pandemia del coronavirus (COVID-19) irrumpió en la vida de las personas alrededor del mundo, (OMS, 2020) propició cambios en la forma de trabajar y de estudiar. Para los estudiantes representa un reto. La comunidad educativa ha realizado esfuerzos para sostener el aprendizaje de los estudiantes; esto representó la necesidad del uso de las tecnologías de la información y depender de sus propios recursos para garantizar la continuidad del aprendizaje obligándolos a tomar clases a distancia por medios digitales (UNESCO, 2020). Esta investigación permitirá conocer las condiciones y cómo enfrentan los desafíos el estudiantado del área EconómicoAdministrativa de la Universidad Tecnológica de León. Para eso se diseñó un cuestionario con el fin de recolectar información, se validó para medir la confiabilidad y se aplicó a una muestra de 249 estudiantes. Se analizaron los datos y mostraron cuántos de ellos tienen computadora; si es de uso exclusivo o la comparten; cuántos cuentan con internet y la calidad del servicio; cuántos tienen teléfonos celulares; cuántas horas utilizan sus dispositivos para las clases; las plataformas que utilizan; si cuentan con lo necesario para trabajar en sus casas y si prefieren las clases a distancia o presenciales.
\end{abstract}

COVID-19, Educación en línea, TICS

\begin{abstract}
The coronavirus pandemic (COVID-19) broke into the lives of people around the world, (WHO, 2020) led to changes in the way of working and studying. For students it represents a challenge. The educational community has made efforts to sustain student learning; This represented the need to use information technologies and depend on their own resources to guarantee the continuity of learning, forcing them to take distance classes through digital means (UNESCO, 2020). This research will allow to know the conditions and how the students of the Administrative Economic area of the Technological University of León face the challenges. For this, a questionnaire was designed in order to collect information, it was validated to measure reliability and it was applied to a sample of 249 students. The data was analyzed and showed how many of them have a computer; if it is for exclusive use or shared; how many have internet and the quality of the service; how many have cell phones; how many hours they use their devices for classes; the platforms they use; if they have what it takes to work at home and if they prefer distance or face-to-face classes.
\end{abstract}

COVID-19, Online Eduction, TICS

Citación: QUEZADA-FLORES, Ma. de la Luz, MÁRQUEZ-DE ANDA, Camilo, SERRANO-TORRES, Ma. Guadalupe y GONZÁLEZ-ARREDONDO, Liliana. Educación en línea en tiempos de COVID-19 en el área económico-administrativa en la Universidad Tecnológica de León. Revista de Políticas Universitarias. 2020. 4-12:1-10.

\footnotetext{
* Correspondencia del Autor (Correo electrónico: mquezada@utleon.edu.mx)

$\dagger$ Investigador contribuyendo como primer autor.
} 


\section{Introducción}

La economía mundial dio un giro completo e inesperado. El año anterior apareció un ser diminuto que colapsó los planes económicos financieros y de salud del mundo entero. La aparición del virus llamado COVID-19, transformó la vida de todo ser humano. Esta transformación ha dado como resultado nuevas formas de relacionarse, entre las sociedades de cada país y entre los diferentes países.

Dada la condición de reclusión para evitar la propagación del virus, las escuelas y universidades modificaron sus modelos y ahora las clases han tenido que ser a distancia. Lo anterior conduce a la necesidad de tener los conocimientos suficientes del uso de las tecnologías necesarias, para poder acceder a las clases en línea. Además de los conocimientos, es necesario contar con los instrumentos para tener ese acceso.

La situación de reclusión ha traído consecuencias en la economía de las familias. Al no poder trasladarse a sus respectivos lugares de trabajo, dejaron de percibir ingresos y se vieron en la necesidad de ajustar de manera sustancial su presupuesto de gastos. Entre las nuevas necesidades que aparecen, están los gastos de internet $y$ dispositivos que permitan la comunicación a través de ella.

Esta manera diferente de relación da lugar a la formación de nuevos hábitos de comportamiento, que por supuesto originan resultados diversos en las actividades cotidianas de los seres humanos. Estos resultados deben ser conocidos, para determinar si los hábitos, recientemente creados, darán mejores, o peores resultados en el aprendizaje del estudiantado, de tal manera que se pueda atender a las necesidades de la nueva realidad.

\section{Justificación}

Esta investigación permitirá conocer el impacto de esta pandemia, en los nuevos hábitos de estudio y en el aprovechamiento escolar en el estudiantado. Conoceremos también si el alumnado y personal docente cuentan con las habilidades necesarias para desenvolverse de manera exitosa en este nuevo modelo educativo.
Tanto el gobierno como las instituciones deberán proporcionar los medios para que el personal docente y estudiantes cuenten con los conocimientos y herramientas necesarias para su gestión.

\section{Problema}

La crisis existente originada por la expansión del COVID-19, ha representado problemas para mantener un aprovechamiento escolar eficiente, de la educación a distancia a causa de los factores secundarios que representa esta amenaza a la salud.

\section{Preguntas de investigación}

¿Los alumnos del área EconómicoAdministrativa de la Universidad Tecnológica de León, cuentan con las herramientas necesarias para mantener su rendimiento escolar, ¿en medio de esta crisis?

\section{Hipótesis}

Los alumnos del área EconómicoAdministrativa de la de la Universidad Tecnológica de León, no cuentan con todos los medios para mantener de manera óptima, el rendimiento escolar en esta crisis, generada por la pandemia.

\section{Objetivo general}

Conocer las condiciones y cómo enfrentan los desafíos de esta nueva realidad los alumnos del área Económico-Administrativa de la Universidad Tecnológica de León.

\section{Marco Teórico}

\section{Situación actual}

A nivel mundial estudiantes y jóvenes de todo el planeta están o han sido afectados por el cierre de escuelas y universidades debido a la pandemia de la COVID-19. (UNESCO, 2020). Los coronavirus son una familia de virus que causan enfermedades entre humanos y animales. Se trata del SARS-COV2. Apareció en China en diciembre del año 2019 y provoca una enfermedad llamada COVID-19, que se extendió por el mundo y fue declarada pandemia global por la Organización Mundial de la Salud. (Gobierno de México, 2020). 
La transmisión de persona a persona de la infección por COVID-19 llevó al aislamiento y se han implementado amplias medidas para reducir la transmisión en poblaciones susceptibles, incluidos niños, jóvenes, adultos, personal médico y personas mayores. (Hussin A. Rothan, 2020) La actual pandemia representa una amenaza para el avance de la educación en todo el mundo, ya que tiene impactos significativos, el cierre de las escuelas de todos los niveles y la recesión económica generada por las medidas de control de la pandemia tendrán un costo a largo plazo sobre el capital humano y el bienestar. Se debe actuar con rapidez, se pueden reformar los sistemas de educación después de la pandemia, de modo de estar mejor preparados para afrontar crisis futuras. (Banco Mundial, 2020)

En México se publica el 02/03/20 en el Diario Oficial de la Federación el acuerdo por el que se suspenden las clases en las escuelas de educación preescolar, primaria, secundaria, normal y demás para la formación de maestros de educación básica del sistema educativo nacional, así como aquellas de tipos medio superior y superior dependientes de la secretaría de educación pública (Secretaría de Educación Pública, 2020).

\section{Educación en línea}

Con la pandemia del COVID-19 se vio afectada también la educación superior, pues éstas cerraron y pasaron de clases presenciales al aprendizaje en línea, aunque con dificultades, lo cual ocasionó interrupciones en las trayectorias de aprendizaje y el avance en los estudios. (Organización para la cooperación y el desarrollo economicos, 2020)

De acuerdo con el estudio del Programa de las Naciones Unidas para el Desarrollo, el $55.7 \%$ de los estudiantes no cuentan con el equipo de computación apto para reforzar las clases a distancia. El estudio aborda la amplia necesidad que representa el uso de los medios digitales y tecnológicos en todos los niveles educativos. Por lo cual en México únicamente el 44.3 por ciento de los hogares cuenta con una computadora.

\section{Disponibilidad de dispositivos y conexión}

Para participar de forma activa en la educación en línea es indispensable contar con una computadora o dispositivo además de conexión a internet, ya que profesor y alumno coinciden a través de una plataforma para revisar y descargar documentos, presentaciones en diapositivas o videos. Esta modalidad es sincrónica, es decir el profesor y los alumnos coinciden en el horario. A través de video llamadas; las clases son en vivo y permiten implementar diversas técnicas de enseñanza y permite en tiempo real, aclarar dudas y ofrecer retroalimentación. Además, las plataformas permiten grabar las video clases y archivar los materiales de clase, en caso de que algún estudiante no haya asistido, para posteriores consultas. Pero, será que las condiciones y cómo enfrentan los desafíos de esta nueva realidad está cubierto para el alumnado del área Económico-Administrativa de la Universidad Tecnológica de León.

Según la Encuesta Nacional Sobre Disponibilidad y Uso de Tecnologías de la Información en los Hogares (ENDUTIH) 2019 del Instituto Nacional de Estadística y Geografía (Inegi), el 53.3\% de los hogares que no cuentan con una computadora es por la falta de recursos económicos; $20.9 \%$ porque no les interesa; $16.5 \%$ porque no saben usarla, y $5.6 \%$ porque usan un celular inteligente (Smartphone) u otro dispositivo para conectarse a internet.

El 43.0\% de la población de 6 años o más es usuaria de computadora (49.4 millones). La proporción de hogares que disponen de computadora registró un descenso marginal, al pasar de $44.9 \%$ en 2015 y 2018 a $44.3 \%$ en 2019 , lo que significa una reducción de 0.6 puntos porcentuales.

Con relación a la telefonía celular se estima que el país cuenta con 86.5 millones de usuarios de esta tecnología, lo que representa el $75.1 \%$ de la población de seis años o más y un incremento de 3.6 puntos porcentuales respecto de 2015. Nueve de cada diez usuarios de teléfono celular disponen de un celular inteligente (Smartphone). 
En México hay 80.6 millones de usuarios de Internet, que representan el $70.1 \%$ de la población de seis años o más. Se estima en 20.1 millones el número de hogares que disponen de Internet (56.4\%), ya sea mediante una conexión fija o móvil. De los 80.6 millones de usuarios de Internet de seis años o más, $51.6 \%$ son mujeres y $48.4 \%$ son hombres. Los tres principales medios para la conexión de usuarios a Internet en 2019 fueron: celular inteligente (Smartphone) con 95.3\%; computadora portátil con $33.2 \%$, y computadora de escritorio con 28.9 por ciento. Las principales actividades de los usuarios de Internet en 2019 correspondieron a entretenimiento $91.5 \%$, obtención de información $90.7 \%$ y comunicarse $90.6 \%$. (INEGI, 2020).

\section{Metodología}

La pandemia por COVID-19 existente, ha provocado una crisis multifactorial. Los efectos de la crisis se han ido considerando y midiendo en cuanto al impacto social, económico, de salud y político; sin embargo, existen efectos secundarios que no se han medido y que afectan de manera diferente al interior de cada país.

Atendiendo a esta necesidad, la Universidad Politécnica de San Luis Potosí, convocó a las redes de colaboración que vienen participando con ella en la investigación de diversos temas, a emprender una investigación sobre estos efectos secundarios, en los diferentes sectores de la población del país.

Con el fin de llevar a cabo la investigación se definieron el tipo de investigación y las variables a investigar, así como las técnicas de obtención de datos, población, muestra, instrumentos, validez y confiabilidad y procedimiento para análisis de resultados.

Como parte de este trabajo, se realizó mediante la colaboración llevar a cabo la investigación, de conformidad con los lineamientos señalados por ellos. Como técnica para recolección de la información se aplicó un cuestionario diseñado por ellos, el cual ya había sido validado y determinada su confiablidad, (como ya se señaló anteriormente).
Este cuestionario se aplicó de forma virtual a los alumnos de la carrera de Administración, del área EconómicoAdministrativa de la Universidad Tecnológica de León. En total fueron 249 alumnos los que respondieron de manera adecuada el cuestionario y fueron los cuestionarios que se sumaron a los recolectados por los demás participantes en este proyecto.

En este reporte, se seleccionaron solamente los factores que se refieren a la necesidad del uso de las tecnologías de la información y conocer si cuentan con recursos para garantizar la continuidad del aprendizaje y tomar clases a distancia por medios digitales (UNESCO, 2020).

Comparando además la situación que vivían y por la que están transitando actualmente respecto de este tema.

De toda esta serie de ítems que se refieren a lo citado antes, se tomaron solamente algunos, que se consideraron más significativos por los resultados encontrados y que reflejan de manera clara, las condiciones que manifiestan los alumnos, respecto al peligro de infección y en cuanto a los cambios que representan, el adquirir nuevos hábitos de estudio y el uso de herramientas digitales y las condiciones de éstas. También se tomaron en cuenta los resultados acerca del tiempo que actualmente dedican a sus estudios lo cual representa cumplir con sus actividades escolares.

\section{Resultados}

A continuación, se presentan los resultados de la investigación:

En la tabla 1, se puede observar que del estudiantado que participó en el estudio tan sólo una quinta parte está representada por hombres; en el área económico-administrativa la proporción de mujeres es siempre mucho mayor, ya que los hombres manifiestan preferencia por otras carreras de carácter tecnológico.

\begin{tabular}{|l|r|r|}
\hline Descripción & Número & Porcentaje \\
\hline Hombre & 51 & $20 \%$ \\
\hline Mujer & 198 & $80 \%$ \\
\hline
\end{tabular}

Tabla 1 Género

Fuente: Elaboración propia 
En la siguiente tabla se muestra que el $76 \%$ viven con sus padres. La mayoría son solteros y dependientes de estos.

\begin{tabular}{|l|r|r|}
\hline \multicolumn{1}{|c|}{ Descripción } & \multicolumn{1}{c|}{ Número } & Porcentaje \\
\hline Ambos padres & 188 & $76 \%$ \\
\hline Con mi madre & 46 & $18 \%$ \\
\hline Con mi padre & 7 & $3 \%$ \\
\hline Con alguien & 6 & $2 \%$ \\
\hline Solo & 2 & $1 \%$ \\
\hline
\end{tabular}

Tabla 2 Actualmente vivo con Fuente: Elaboración propia

La tabla 3 muestra el número de personas con las que viven los encuestados e indican con cuántas personas interactúan. Los resultados muestran que casi el $80 \%$ conviven en promedio con cinco personas con la posibilidad de compartir recursos.

\begin{tabular}{|l|r|r|}
\hline Descripción & Número & Porcentaje \\
\hline De 1 a 3 & 31 & $12 \%$ \\
\hline De 4 a 6 & 165 & $66 \%$ \\
\hline De 7 a 9 & 38 & $15 \%$ \\
\hline Más de 10 & 8 & $3 \%$ \\
\hline
\end{tabular}

Tabla 3 ¿Cuántas personas viven en casa incluyéndote? Fuente: Elaboración propia

La tabla 4 muestra la opinión acerca de la gravedad de la pandemia, casi el $80 \%$ de los encuestados manifiesta que es de grave a muy grave.

\begin{tabular}{|l|r|r|}
\hline Escala & Número & Porcentaje \\
\hline Muy grave & 72 & $29 \%$ \\
\hline Grave & 121 & $49 \%$ \\
\hline Regular & 46 & $18 \%$ \\
\hline Poco grave & 10 & $4 \%$ \\
\hline
\end{tabular}

Tabla 4 ¿Qué tan grave consideras que es la infección por coronavirus?

Fuente: Elaboración propia

Con relación a la pregunta ¿Tienes computadora en casa? la tabla 5 muestra que más del $70 \%$ de los encuestados cuentan con equipo de cómputo.

\begin{tabular}{|l|r|r|}
\hline Escala & Número & Porcentaje \\
\hline $\mathrm{Si}$ & 180 & $72 \%$ \\
\hline $\mathrm{No}$ & 69 & $28 \%$ \\
\hline
\end{tabular}

Tabla 5 ¿Tienes computadora en casa? Fuente: Elaboración propia

La tabla 6 muestra como respuesta a la pregunta: La computadora donde trabajas es de uso exclusivo o la compartes; el $74 \%$ de los encuestados debe compartirlo con otros miembros de la familia.

\begin{tabular}{|l|r|r|}
\hline \multicolumn{1}{|c|}{ Escala } & Número & Porcentaje \\
\hline De uso exclusivo & 65 & $26 \%$ \\
\hline La comparto & 184 & $74 \%$ \\
\hline
\end{tabular}

Tabla 6 La computadora donde trabajas es Fuente: Elaboración propia

Podemos observar que en respuesta a la pregunta ¿Tienes Internet en casa? casi el 90\% de los estudiantes encuestados cuentan con conexión de internet.

\begin{tabular}{|l|r|r|}
\hline Escala & Número & Porcentaje \\
\hline $\mathrm{Si}$ & 219 & $88 \%$ \\
\hline No & 30 & $12 \%$ \\
\hline
\end{tabular}

Tabla 7 ¿Tienes Internet en casa? Fuente: Elaboración propia

En la tabla 8, respecto de la conexión de internet los encuestados manifiesta tan solo el $8 \%$ que la conexión es rápida, el $50 \%$ que la conexión es regular y el $42 \%$ opinan que es lento o muy lento.

\begin{tabular}{|l|r|r|}
\hline \multicolumn{1}{|c|}{ Escala } & Número & Porcentaje \\
\hline Rápido & 20 & $8 \%$ \\
\hline Velocidad regular & 124 & $50 \%$ \\
\hline Lento & 64 & $26 \%$ \\
\hline Muy Lento & 41 & $16 \%$ \\
\hline
\end{tabular}

Tabla 8 El internet en casa es:

Fuente: Elaboración propia

De acuerdo con la pregunta ¿Antes de la pandemia habías tomado cursos por internet? En la tabla 9; el 94\% afirma que antes de la pandemia nunca había tomado cursos por internet.

\begin{tabular}{|l|r|r|}
\hline Escala & Número & Porcentaje \\
\hline $\mathrm{Si}$ & 14 & $6 \%$ \\
\hline No & 235 & $94 \%$ \\
\hline
\end{tabular}

Tabla 9 Antes de la pandemia ¿Habías tomado cursos por internet?

Fuente: Elaboración propia

A la pregunta Horas al día que usabas TIC antes de la pandemia. Casi el $90 \%$ de los encuestados usaban en promedio de 1 a 6 horas diferentes dispositivos e internet según la tabla 10.

\begin{tabular}{|l|r|r|}
\hline Escala & Número & Porcentaje \\
\hline De 1 a 3 horas & 117 & $47 \%$ \\
\hline De 4 a 6 horas & 105 & $42 \%$ \\
\hline De 7 a 9 horas & 19 & $8 \%$ \\
\hline Más de 10 horas & 8 & $3 \%$ \\
\hline
\end{tabular}

Tabla 10 Horas al día que usabas TIC (Internet, Celular, Tablet o la Computadora) antes de la pandemia Fuente: Elaboración propia

QUEZADA-FLORES, Ma. de la Luz, MÁRQUEZ-DE ANDA, Camilo, SERRANO-TORRES, Ma. Guadalupe y GONZÁLEZ-ARREDONDO, Liliana. Educación en línea en tiempos de COVID-19 en el área económico-administrativa en la Universidad Tecnológica de León. Revista de Políticas Universitarias. 2020 
Durante la pandemia de acuerdo con la pregunta Horas al día que usas TIC ahora en pandemia. La tabla 11 muestra que casi el $85 \%$ de los encuestados usan en promedio diferentes dispositivos e internet, entre 7 y 10 horas diarias.

\begin{tabular}{|l|r|r|}
\hline \multicolumn{1}{|c|}{ Escala } & Número & Porcentaje \\
\hline De 1 a 3 horas & 13 & $5 \%$ \\
\hline De 4 a 6 horas & 29 & $12 \%$ \\
\hline De 7 a 10 horas & 119 & $48 \%$ \\
\hline Más de 10 horas & 88 & $35 \%$ \\
\hline
\end{tabular}

Tabla 11 Horas al día que usas TIC (Internet, Celular, Tablet o la Computadora) ahora en pandemia Fuente: Elaboración propia

En el manejo de Office el $28 \%$ de los encuestados afirma manejarlo muy alto y alto y el 65\% manifiesta manejarlo medianamente; y un $6 \%$ dice manejarlo bajo y muy bajo.

\begin{tabular}{|l|r|r|}
\hline \multicolumn{1}{|c|}{ Escala } & Número & Porcentaje \\
\hline Muy alto & 9 & $4 \%$ \\
\hline Alto & 61 & $24 \%$ \\
\hline Medio & 163 & $65 \%$ \\
\hline Bajo & 11 & $4 \%$ \\
\hline Muy Bajo & 5 & $2 \%$ \\
\hline
\end{tabular}

Tabla 12 Tu manejo de Office (Word, Excel, Power Point) es:

Fuente: Elaboración propia

Las plataformas a las que tienes o has tenido acceso durante el período de la pandemia muestra la tabla 13, que todos los encuestados manejan diversas plataformas como Teams, Zoom, Moodle, WhatsApp, WebEx, Skipe para el manejo de la modalidad a distancia de sus clases.

\begin{tabular}{|l|r|r|}
\hline \multicolumn{1}{|c|}{ Escala Número } & Porcentaje \\
\hline $\begin{array}{l}\text { Teams, Zoom, Moodle, } \\
\text { WhatsApp, WebEx, Skipe. }\end{array}$ & 82 & $33 \%$ \\
\hline Teams, Zoom, WhatsApp & 167 & $67 \%$ \\
\hline
\end{tabular}

Tabla 13 Plataformas a las que tienes o has tenido acceso durante el periodo de la pandemia:

Fuente: Elaboración propia

A la pregunta ¿Usas Facebook? En la tabla 14, el $95 \%$ de los encuestados usan Facebook y solo el 5\% no lo utiliza.

\begin{tabular}{|l|r|r|}
\hline Escala & Número & Porcentaje \\
\hline $\mathrm{Si}$ & 237 & $95 \%$ \\
\hline No & 12 & $5 \%$ \\
\hline
\end{tabular}

Tabla 14. ¿Usas facebook?

Fuente: Elaboración propia
Podemos observar en la tabla 15 que el 96\% de los encuestados tienen teléfono celular.

\begin{tabular}{|c|c|c|}
\hline Escala & Número & Porcentaje \\
\hline $\mathrm{Si}$ & 239 & $96^{\circ}$ \\
\hline No & 11 & $4^{c}$ \\
\hline
\end{tabular}

Tabla 15 ¿Tienes teléfono celular? Fuente: Elaboración propia

De los estudiantes que tienen teléfono celular, el $91 \%$ tienen acceso a internet y el $9 \%$ no cuenta con servicio de internet.

\begin{tabular}{|l|r|r|}
\hline Escala & Número & Porcentaje \\
\hline $\mathrm{Si}$ & 227 & $91 \%$ \\
\hline $\mathrm{No}$ & 22 & $9 \%$ \\
\hline
\end{tabular}

Tabla 16 ¿Tu teléfono celular tiene acceso a internet? Fuente: Elaboración propia

De acuerdo con la tabla 17 se aprecia que el $84 \%$ de los encuestado usa su teléfono celular para conectarse a las sesiones de clase vía internet.

\begin{tabular}{|l|r|r|}
\hline Escala & Número & Porcentaje \\
\hline $\mathrm{Si}$ & 209 & $84 \%$ \\
\hline No & 40 & $16 \%$ \\
\hline
\end{tabular}

Tabla 17 ¿Usas tu teléfono celular para conectarte a las sesiones de clase vía internet?

Fuente: Elaboración propia

Con respecto a la pregunta ¿Qué tan de acuerdo están en preferir una formación presencial? los encuestados están de acuerdo y muy de acuerdo con ésta en un $72 \%$, un $4 \%$ no está de acuerdo ni en desacuerdo y un $24 \%$ están en desacuerdo y muy en desacuerdo.

\begin{tabular}{|l|r|r|}
\hline \multicolumn{1}{|c|}{ Escala } & Número & Porcentaje \\
\hline Muy de acuerdo & 150 & $60 \%$ \\
\hline De acuerdo & 31 & $12 \%$ \\
\hline Ni de acuerdo ni desacuerdo & 9 & $4 \%$ \\
\hline En desacuerdo & 16 & $6 \%$ \\
\hline Muy en desacuerdo & 43 & $17 \%$ \\
\hline
\end{tabular}

Tabla 18 ¿Qué tan de acuerdo están con las siguientes sentencias? Prefiero una formación presencial

Fuente: Elaboración propia

En referencia a la pregunta $¿ \mathrm{La}$ formación presencial requiere menos carga de trabajo? El 56\% están muy de acuerdo y de acuerdo, el 9\% no están ni de acuerdo ni en desacuerdo y el $25 \%$ están en desacuerdo y muy en desacuerdo. 
Diciembre, 2020 Vol.4 No.12 1-10

\begin{tabular}{|l|r|r|}
\hline \multicolumn{1}{|c|}{ Escala } & Número & Porcentaje \\
\hline Muy de acuerdo & 68 & $27 \%$ \\
\hline De acuerdo & 72 & $29 \%$ \\
\hline Ni de acuerdo ni desacuerdo & 45 & $18 \%$ \\
\hline En desacuerdo & 23 & $9 \%$ \\
\hline Muy en desacuerdo & 41 & $16 \%$ \\
\hline
\end{tabular}

Tabla 19 ¿Qué tan de acuerdo están con las sentencias? La formación presencial requiere menos carga de trabajo Fuente: Elaboración propia

En la tabla 20 podemos observar que los encuestados en relación con la pregunta ¿La mayoría de las clases las prefiero presenciales? El 73\% está muy de acuerdo y de acuerdo en la modalidad presencial, el $4 \%$ no están ni de acuerdo ni en desacuerdo y el $22 \%$ están en desacuerdo y muy en desacuerdo.

\begin{tabular}{|l|r|r|}
\hline \multicolumn{1}{|c|}{ Escala } & Número & Porcentaje \\
\hline Muy de acuerdo & 143 & $57 \%$ \\
\hline De acuerdo & 39 & $16 \%$ \\
\hline Ni de acuerdo ni desacuerdo & 10 & $4 \%$ \\
\hline En desacuerdo & 16 & $6 \%$ \\
\hline Muy en desacuerdo & 41 & $16 \%$ \\
\hline
\end{tabular}

Tabla 20 ¿Qué tan de acuerdo están con las siguientes sentencias? La mayoría de las clases las prefiero presenciales

Fuente: Elaboración propia

En la siguiente tabla podemos observar que los encuestados en relación con la pregunta ¿Las explicaciones de los docentes son mejores en clase presencial? El $70 \%$ está muy de acuerdo y de acuerdo en la modalidad presencial, el $7 \%$ no están ni de acuerdo ni en desacuerdo y el $23 \%$ están en desacuerdo y muy en desacuerdo.

\begin{tabular}{|l|r|r|}
\hline \multicolumn{1}{|c|}{ Escala } & Número & Porcentaje \\
\hline Muy de acuerdo & 144 & $58 \%$ \\
\hline De acuerdo & 30 & $12 \%$ \\
\hline Ni de acuerdo ni desacuerdo & 17 & $7 \%$ \\
\hline En desacuerdo & 15 & $6 \%$ \\
\hline Muy en desacuerdo & 43 & $17 \%$ \\
\hline
\end{tabular}

Tabla 21 ¿Qué tan de acuerdo están con las siguientes sentencias? Las explicaciones de los docentes son mejores en clase presencial

Fuente: Elaboración propia

En la tabla 22, los encuestados responden a la pregunta $i$ Las plataformas en internet son un problema para la educación a distancia por la carga de trabajo? Opinan estar muy de acuerdo y de acuerdo el 34\%; mismo porcentaje de encuestados están en desacuerdo y muy en desacuerdo.

\begin{tabular}{|l|r|r|}
\hline Escala & Número & Porcentaje \\
\hline Muy de acuerdo & 38 & $15 \%$ \\
\hline De acuerdo & 47 & $19 \%$ \\
\hline Ni de acuerdo ni desacuerdo & 79 & $32 \%$ \\
\hline En desacuerdo & 56 & $22 \%$ \\
\hline Muy en desacuerdo & 29 & $12 \%$ \\
\hline
\end{tabular}

Tabla 22 ¿Qué tan de acuerdo están con las siguientes sentencias? Las plataformas en internet son un problema para la educación a distancia

Fuente: Elaboración propia

Con respeto a la pregunta $¿$ Los maestros están muy preparados para la educación en línea? Los encuestados en un 34\% están muy de acuerdo y de acuerdo; considerando que el personal docente también tuvo que adaptarse a los nuevos conceptos pedagógicos y modos de impartir la enseñanza, y no están ni de acuerdo ni en desacuerdo el $38 \%$ porcentaje casi similar a los que están en desacuerdo y muy en desacuerdo.

\begin{tabular}{|l|r|r|}
\hline \multicolumn{1}{|c|}{ Escala } & Número & Porcentaje \\
\hline Muy de acuerdo & 14 & $6 \%$ \\
\hline De acuerdo & 44 & $18 \%$ \\
\hline Ni de acuerdo ni desacuerdo & 94 & $38 \%$ \\
\hline En desacuerdo & 63 & $25 \%$ \\
\hline Muy en desacuerdo & 34 & $14 \%$ \\
\hline
\end{tabular}

Tabla 23 ¿Qué tan de acuerdo están con las siguientes sentencias? Los maestros están muy preparados para la educación en línea

Fuente: Elaboración propia

Con respecto a la siguiente afirmación: ¿Me gusta más la educación a distancia? los encuestados están muy de acuerdo y de acuerdo en un $10 \%$, no estando de acuerdo ni de acuerdo ni en desacuerdo en un $13 \%$, y responden en un $77 \%$ estar en desacuerdo y muy en desacuerdo con la afirmación antes citada.

\begin{tabular}{|l|r|r|}
\hline \multicolumn{1}{|c|}{ Escala } & Número & Porcentaje \\
\hline Muy de acuerdo & 14 & $6 \%$ \\
\hline De acuerdo & 9 & $4 \%$ \\
\hline Ni de acuerdo ni desacuerdo & 33 & $13 \%$ \\
\hline En desacuerdo & 80 & $32 \%$ \\
\hline Muy en desacuerdo & 113 & $45 \%$ \\
\hline
\end{tabular}

Tabla 24 ¿Qué tan de acuerdo están con las siguientes sentencias? Me gusta más la educación a distancia Fuente: Elaboración propia

En relación con la afirmación: En casa tengo todo lo que necesito para una educación en línea, el $22 \%$ de los encuestados se muestran muy de acuerdo y de acuerdo, manifiesta el $29 \%$ ni de acuerdo ni en desacuerdo y el $49 \%$ está en desacuerdo y muy en desacuerdo. 
Diciembre, 2020 Vol.4 No.12 1-10

\begin{tabular}{|l|r|r|}
\hline \multicolumn{1}{|c|}{ Escala } & Número & Porcentaje \\
\hline Muy de acuerdo & 13 & $5 \%$ \\
\hline De acuerdo & 43 & $17 \%$ \\
\hline Ni de acuerdo ni desacuerdo & 73 & $29 \%$ \\
\hline En desacuerdo & 76 & $31 \%$ \\
\hline Muy en desacuerdo & 44 & $18 \%$ \\
\hline
\end{tabular}

Tabla 25 ¿Qué tan de acuerdo están con las siguientes sentencias? En casa tengo todo lo que necesito para una educación en línea

Fuente: Elaboración propia

En correspondencia con la afirmación: Dispongo de todo el material para mis clases en línea, el $31 \%$ de los encuestados se muestran muy de acuerdo y de acuerdo, manifiesta el $22 \%$ ni de acuerdo ni en desacuerdo y el $48 \%$ está en desacuerdo y muy en desacuerdo.

\begin{tabular}{|l|r|r|}
\hline Escala & Número & Porcentaje \\
\hline Muy de acuerdo & 17 & $7 \%$ \\
\hline De acuerdo & 59 & $24 \%$ \\
\hline Ni de acuerdo ni desacuerdo & 54 & $22 \%$ \\
\hline En desacuerdo & 71 & $29 \%$ \\
\hline Muy en desacuerdo & 48 & $19 \%$ \\
\hline
\end{tabular}

Tabla 26 ¿Qué tan de acuerdo están con las siguientes sentencias? Dispongo de todo el material para mis clases en línea

Fuente: Elaboración propia

Los encuestados contestaron a la siguiente afirmación: La manera de evaluar es más fácil y transparente en línea, el 16\% de los encuestados se muestran muy de acuerdo y de acuerdo, contesta el 39\% ni de acuerdo ni en desacuerdo y el $45 \%$ está en desacuerdo y muy en desacuerdo.

\begin{tabular}{|l|r|r|}
\hline \multicolumn{1}{|c|}{ Escala } & Número & Porcentaje \\
\hline Muy de acuerdo & 14 & $6 \%$ \\
\hline De acuerdo & 24 & $10 \%$ \\
\hline Ni de acuerdo ni desacuerdo & 98 & $39 \%$ \\
\hline En desacuerdo & 60 & $24 \%$ \\
\hline Muy en desacuerdo & 53 & $21 \%$ \\
\hline
\end{tabular}

Tabla 27 ¿Qué tan de acuerdo están con las siguientes sentencias? La manera de evaluar es más fácil y transparente en línea

Fuente: Elaboración propia

El 62\% de los encuestados están muy de acuerdo y de acuerdo con la afirmación: Las cargas de trabajo son mayores en educación a distancia, el $12 \%$ expresan que no están ni de acuerdo ni en desacuerdo y el $26 \%$ está en desacuerdo y muy en desacuerdo.

\begin{tabular}{|l|r|r|}
\hline \multicolumn{1}{|c|}{ Escala } & Número & Porcentaje \\
\hline Muy de acuerdo & 95 & $38 \%$ \\
\hline De acuerdo & 59 & $24 \%$ \\
\hline Ni de acuerdo ni desacuerdo & 31 & $12 \%$ \\
\hline En desacuerdo & 29 & $12 \%$ \\
\hline Muy en desacuerdo & 35 & $14 \%$ \\
\hline
\end{tabular}

Tabla 28 ¿Qué tan de acuerdo están con las siguientes sentencias? Las cargas de trabajo son mayores en educación en línea

Fuente: Elaboración propia

En la tabla 28 se observa que el $20 \%$ de los encuestados están muy de acuerdo y de acuerdo con la afirmación: El aprendizaje en clase depende más del profesor, manifiesta el 45\% que no están ni de acuerdo ni en desacuerdo y el 35\% está en desacuerdo y muy en desacuerdo.

\begin{tabular}{|l|r|r|}
\hline \multicolumn{1}{|c|}{ Escala } & Número & Porcentaje \\
\hline Muy de acuerdo & 15 & $6 \%$ \\
\hline De acuerdo & 34 & $14 \%$ \\
\hline Ni de acuerdo ni desacuerdo & 112 & $45 \%$ \\
\hline En desacuerdo & 65 & $26 \%$ \\
\hline Muy en desacuerdo & 23 & $9 \%$ \\
\hline
\end{tabular}

Tabla 29 ¿Qué tan de acuerdo están con las siguientes sentencias? El aprendizaje en clase depende más del profesor

Fuente: Elaboración propia

Con respecto a la afirmación: El aprendizaje en línea depende más del estudiante, el $43 \%$ de los encuestados están muy de acuerdo y de acuerdo, ni de acuerdo ni en desacuerdo el $31 \%$ y el $27 \%$ está en desacuerdo y muy en desacuerdo.

\begin{tabular}{|l|r|r|}
\hline \multicolumn{1}{|c|}{ Escala } & Número & Porcentaje \\
\hline Muy de acuerdo & 52 & $21 \%$ \\
\hline De acuerdo & 55 & $22 \%$ \\
\hline Ni de acuerdo ni desacuerdo & 76 & $31 \%$ \\
\hline En desacuerdo & 37 & $15 \%$ \\
\hline Muy en desacuerdo & 29 & $12 \%$ \\
\hline
\end{tabular}

Tabla 30 ¿Qué tan de acuerdo están con las siguientes sentencias? El aprendizaje en línea depende más del estudiante

Fuente: Elaboración propia

\section{Conclusiones}

Los retos a los que se enfrenta el estudiantado del área Económico-Administrativa de la Universidad Tecnológica de León que actualmente cursan asignaturas en la modalidad a distancia, son múltiples en relación con los dispositivos tecnológicos, la conexión a internet, así como su preferencia por las clases presenciales.

QUEZADA-FLORES, Ma de la Luz, MÁRQUEZ-DE ANDA, Camilo, SERRANO-TORRES, Ma. Guadalupe y GONZÁLEZ-ARREDONDO, Liliana. Educación en línea en tiempos de COVID-19 en el área económico-administrativa en la Universidad Tecnológica de León. Revista de Políticas Universitarias. 2020 
El no contar con herramientas tecnológicas, aunado a la crisis económica, contribuye a que los alumnos abandonen sus estudios, y además al interrumpir los hábitos de estudio provoca una pérdida de los conocimientos y creando una desventaja enorme.

El estudiantado enfrenta la crisis con serias desventajas, lo que los convierte en serios aspirantes a desertar de sus estudios y olvidar sus sueños de convertirse en profesionistas. Por esto es necesario implementar un desarrollo más creativo, reflexivo y crítico, que potencialice las herramientas con las que cuenta el estudiantado para llegar a la meta.

Correa y Pablos (2009) afirman que es necesario cambiar la musculación electrónica del personal docente utilizando como herramienta las TICs, ya que la tecnología trae consigo cambios sociales y culturales y es necesario investigar por diferentes métodos los nuevos contextos virtuales, formas de comunicación y roles entre docente - estudiante, autoaprendizaje y autodirección para conocer, difundir, desarrollar e implementar nuevas prácticas didácticas con éxito.

Así en la Universidad Tecnológica de León se han implementado la combinación de plataformas tecnológicas para adaptarnos a esta etapa de pandemia, donde una combinación que ha resultado exitosa es la combinación de Teams de Microsoft y Moodle en la plataforma institucional, Aula Virtual. Logrando que en Teams se tengan las clases de manera síncrona y aprovechando la gran experiencia del docente y comunicación directa con el estudiantado, como si fuera una clase presencial, pero aprovechando la tecnología de manera remota y realizando las tareas y exámenes en Aula virtual, de manera asíncrona, con la finalidad de tener las evidencias de manera institucional y con las ventajas del trabajo de Academia que logra que se unifiquen los desempeños que se desean obtener para las materias del área Económico Administrativo.
Así mismo el estudiantado debe desarrollar competencias de autodirección en el aprendizaje, se refiere al proceso por el cual el alumno se responsabiliza de plantear, implementar y evaluar su propio proceso de aprendizaje, desarrollando habilidades, actitudes y valores necesarios para llegar a un punto de madurez tanto cognitiva como emocional que les permita dirigir en forma eficiente sus recursos para el aprendizaje (Heredia y Sánchez, 2012).

Considerando estas características tanto en el estudiantado como en el personal docente llegamos a la conclusión de que "la enseñanza a distancia debe ser abierta, flexible e interactiva, basada en el uso de las tecnologías de la información (TIC), facilitando la comunicación entre el profesor y alumno con herramientas síncronas y asíncronas" (Ramírez, 2008), con esto en la UTL se tratan de mitigar el no contar con todas las herramientas tecnológicas, en el estudiantado, pero si utilizar al máximo con las que cuentan, para lograr que el estudiantado pueda cumplir sus sueños de terminar sus estudios y ser profesionista.

\section{Referencias}

Banco Mundial. (20 de Noviembre de 2020). bancomundial.org. Obtenido de https://www.bancomundial.org/es/topic/educati on/publication/the-covid19-pandemic-shocksto-education-and-policy-responses

Correa, J. M., Pablos, J. (2009). Nuevas Tecnologías e Innovación educativa. Revista de Psicodidáctica, 14(1), 133-145. Recuperado de: http://www.redalyc.org/articulo.oa?id=1751272 3009 ISSN 1136-1034

Gobierno de México. (20 de Noviembre de 2020). Gobierno de México. Obtenido de https://coronavirus.gob.mx/covid-19/

Heredia Escorza, Y., Sánchez Aradillas, A. L. (2012). Teorías del aprendizaje en el contexto educativo. México: Editorial Digital Tecnológico de Monterrey.

Hussin A. Rothan, S. N. (20 de Noviembre de 2020). sciencedirect.com . Obtenido de https://www.sciencedirect.com/journal/journalof-autoimmunity/vol/109/suppl/C 
INEGI. (21 de Noviembre de 2020). Inegi.org.mx. Obtenido de https://www.inegi.org.mx/contenidos/saladepre nsa/boletines/2020/OtrTemEcon/ENDUTIH_20 19.pdf

OMS. (27 de Abril de 2020). Organización Mundial de la Salud. Obtenido de https://www.who.int/es/news/item/27-04-2020who-timeline---covid-19

Organización para la cooperación y el desarrollo economicos. (21 de Noviembre de 2020). oecd.org. Obtenido de https://www.oecd.org/centrodemexico/medios/ EAG2020_COVID\%20Brochure\%20ES.pdf

Ramírez, M. S. (2008). Dispositivos de mobile learning para ambientes virtuales: Investigación de implicaciones en el diseño y la enseñanza. Apertura Revista de Innovación Educativa, Nueva época, 8(9), 82-96. Recuperado de: http://www.udgvirtual.udg.mx/apertura/index.p hp/apertura4/article/view/108 y en http://catedra.ruv.itesm.mx/handle/987654321/7 02

Secretaría de Educación Pública. (20 de Noviembre de 2020). https://www.dof.gob.mx/. Obtenido de https://www.dof.gob.mx/nota_detalle.php?codi go $=5589479 \&$ fecha $=16 / 03 / 2020$

UNESCO. (2020). UNESCO. Obtenido de https://es.unesco.org/news/surgen-alarmantesbrechas-digitales-aprendizaje-distancia

UNESCO. (20 de Noviembre de 2020). UNESCO. Obtenido de https://es.unesco.org/covid19/globaleducationc oalition 